\title{
VALIDITY OF AN EXPERT SYSTEM FOR OIL SHALE-FIRED CFB BOILER DESIGN AND PERFORMANCE ANALYSIS
}

\author{
WANG QING*', BAI JINGRU, ZHAO LIXIA, \\ SUN BAIZHONG, LIU HONGPENG
}

Northeast Dianli University

132012 Jilin, China

\begin{abstract}
A 65-t/h oil shale-fired circulating fluidized bed (CFB) boiler of low circulation ratio, the earliest prototype operated in the world, was manually designed by our research group twelve years ago using our experience and published data available. On the basis of the long-term operation, it has been demonstrated that all expected performances, such as high combustion efficiency, low emission of $\mathrm{NO}_{x}$ and $\mathrm{SO}_{x}$, stability of operation and flexibility of load change etc., have been reached. For evaluation and confirmation of the manual design, an Expert System (CFBCAD) developed by Greenfield Research Inc. was used to regenerate the boiler. The results from these two approaches were compared and validated, and a reasonable agreement was reached. Finally, the main parameters of the prototype were provided. Some design principles were given and a series of hot operation tests were carried out. The influence of load on the boiler performances such as temperature in the bed and the back pass, and heat loss were assessed and discussed. The properties of self-desulphurization and boiler start-up were also described.
\end{abstract}

\section{Introduction}

Oil shale (OS) is an important source of energy. The estimated resources of OS in China are approximately 2 trillion tonnes, which are equivalent to eighty billion tonnes shale oils. This resource is only next to the United States, Brazil and Estonia, ranked the 4th in the world. As one of energy resources, OS has been developed and utilized for more than one hundred years. There are two primary utilization methods: one is heating OS in a retorting furnace to yield gas and shale oil, which can be utilized directly as fuel oil or be used to produce diesel fuel and various oil products; the other is to burn directly as fuel to generate electricity or heat $[1,2]$.

\footnotetext{
${ }^{*}$ Corresponding author: e-mail rszx@mail.nedu.edu.cn
} 
OS used as a power resource was determined by its combustion means. According to the experiences about OS combustion, there are four disadvantages at pulverized fuel combustion (PF) $[2,3]$ :

(1) huge quantities of OS need to be pulverized; (2) PF needs additional flue gas desulphurizing scrubbers because high combustion temperature does not enable to form $\mathrm{CaSO}_{4}$ in the combustion chamber; (3) PF leads to hard buildups on heating surfaces due to high gas temperatures which cause volatilization of alkali metals present in the fuel. PF may also cause melting of the ash. (4) NOx emissions are also high at PF.

Therefore, fluidized bed combustion/circulating fluidized bed combustion (FBC/CFBC) technologies have begun to attract attentions. The Estonian Power Plants Ltd. is considering CFBC technology for retrofitting its power generation. Two energy blocks each with $215 \mathrm{MWe}_{2}$ equipped with Finland Foster Wheeler circulating fluidized bed boilers, have been set up in 2004, one in the Baltic Power Station and the other in the Estonian Power Station.

In China, the developed 65-t/h low-circulation-ratio oil shale-fired CFB boiler has shown a promising way to burn OS on large scale. Currently there are three such boilers in successful operation for twelve years in Huadian city, Jilin province, China.

This paper concentrates on the design considerations of the boiler and selection of design parameters. The design results of the boiler from an expert system and the manual design will be compared and validated. The manual design program was developed by us twelve years ago via our experience and openly published data available, as well as national standard, that is, the General Methods of Calculation and Design for Industrial Boiler (in Chinese).

\section{Design considerations}

\section{Introduction of the prototype}

The schematic structure of the $65-\mathrm{t} / \mathrm{h}$ oil shale-fired CFB boiler is shown in Fig. 1.

The boiler is a single-drum, natural-circulation, semi-tower type arrangement protected by steel structure. It comprises medium-temperature cyclone, loop seal and ash cooler as well as convective heating surface, superheater, economizer and tubular air heater. With membrane water wall structure, the lower part of the furnace is dense zone, intersection part is free board, and the upper part is convective pass. Superheater and evaporator are placed in the convective pass. Economizer and tubular air heater are placed in the back pass. The medium-temperature cyclone and loop seal are arranged between the furnace and the back pass. 


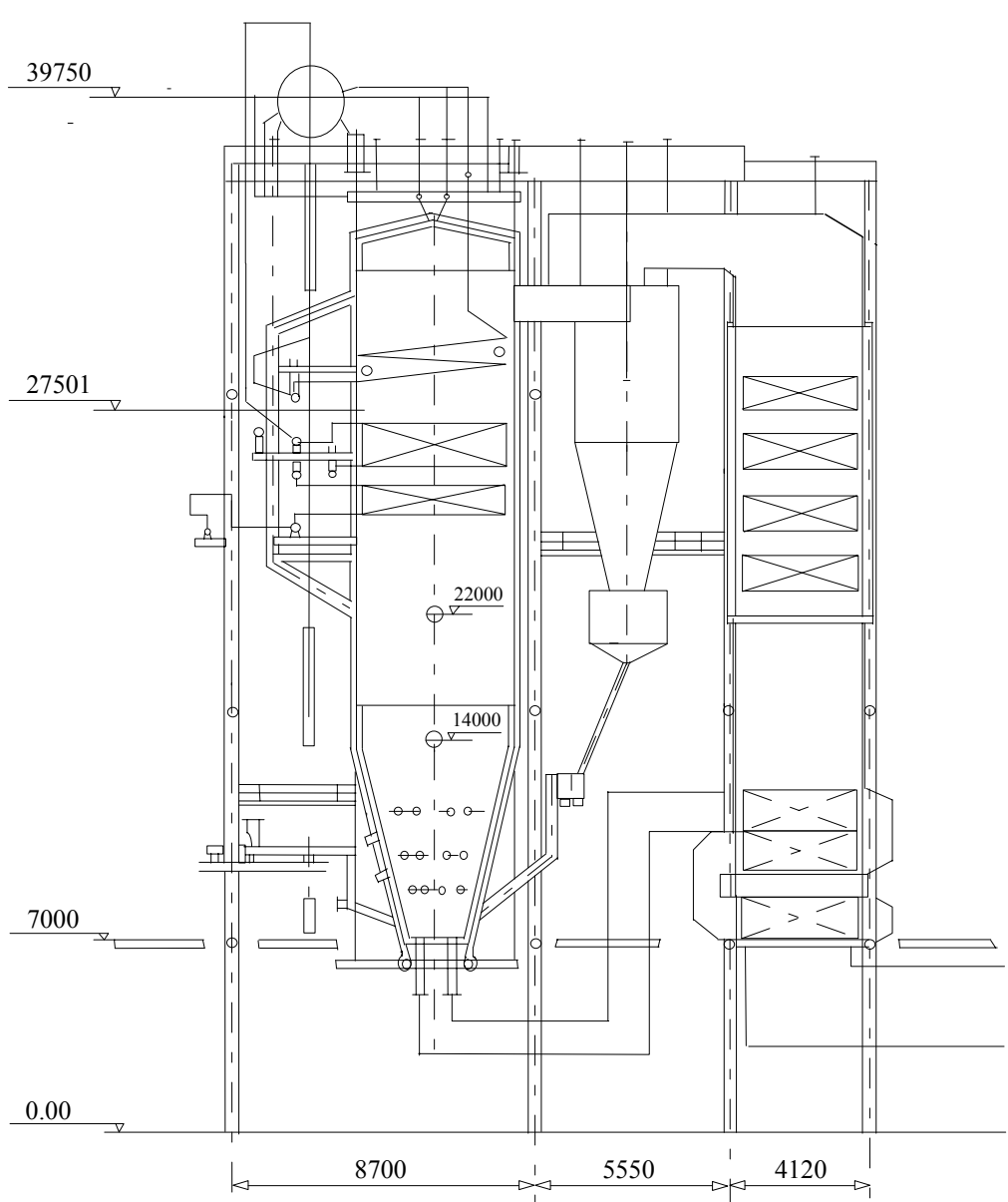

Fig. 1. 65t/h oil shale-fired CFB boiler.

There are four fuel ports in the front wall of the furnace through which the OS $(0-10 \mathrm{~mm})$ is supplied to the furnace. The primary air is introduced from the distributor and the secondary air injected into the furnace from the side walls at three different heights. Temperature in the combustion chamber is kept at around $850^{\circ} \mathrm{C}$. Unburned char and hot solids with high-temperature flue gas leave the convective pass and enter the medium-temperature cyclone, and the collected solids return to the furnace through the standpipe and the loop seal. The loop seal is controlled by high-pressure roots blower, and the solids recycle rate to the furnace is adjusted by changing both air flow rate and pressure drop. To make the adjustment easier, we have arranged an ash silo in the circulation loop. After leaving the cyclone, flue gas exchanges heat with the economizer and the air heater in the back pass and then flows into the electrostatic precipitator (ESP), finally releasing into the atmosphere through the stack. The bottom ash is discharged from the 
bottom of the furnace, cooled to a certain temperature in the ash cooler and then dumped.

The main design parameters and the ultimate analysis of OS are listed in Table 1 and Table 2, respectively. The particle size of OS is in the range of $0-10 \mathrm{~mm}$. No sorbent is needed because of high $\mathrm{CaO}$ content in Huadian OS as indicated in Table 3.

\section{Table. 1. Main design parameters of boiler}

\begin{tabular}{|l|c|}
\hline Main steam flow rate, $\mathrm{kg} / \mathrm{s}$ & 18.06 \\
Feed water temperature, ${ }^{\circ} \mathrm{C}$ & 150 \\
Superheated steam temperature, ${ }^{\circ} \mathrm{C}$ & 450 \\
Superheated steam pressure, $\mathrm{MPa}$ & 5.29 \\
Bed temperature, ${ }^{\circ} \mathrm{C}$ & 850 \\
Cold air temperature, ${ }^{\circ} \mathrm{C}$ & 20 \\
Hot air temperature, ${ }^{\circ} \mathrm{C}$ & 240 \\
Stack gas temperature, ${ }^{\circ} \mathrm{C}$ & 154 \\
Solids' recycle ratio ${ }^{\circ}$ & 7.0 \\
Boiler efficiency, $\%$ & $\geq 85$ \\
Fuel consumption, $\mathrm{kg} / \mathrm{s}$ & 6.525 \\
\hline
\end{tabular}

${ }^{a}$ Ratio of recycling solid mass flow to coal feed rate

Table 2. Proximate and ultimate analysis of Huadian OS (\%, by weight)

\begin{tabular}{|l|c|c|c|c|c|c|c|c|c|}
\hline \multirow{2}{*}{ Fuel } & \multicolumn{4}{|c|}{ Proximate analysis } & \multicolumn{5}{c|}{ Ultimate analysis } \\
\cline { 2 - 10 } & $\mathrm{M}_{\mathrm{ar}}$ & $\mathrm{A}_{\mathrm{ar}}$ & $\mathrm{V}_{\mathrm{daf}}$ & $\mathrm{Q}_{\text {net,ar }}, \mathrm{kJ} / \mathrm{kg}$ & $\mathrm{C}_{\mathrm{ar}}$ & $\mathrm{H}_{\mathrm{ar}}$ & $\mathrm{O}_{\mathrm{ar}}$ & $\mathrm{N}_{\mathrm{ar}}$ & $\mathrm{S}_{\mathrm{ar}}$ \\
\hline Design OS & 10.9 & 54.82 & 80.70 & 8374 & 20.4 & 2.54 & 9.82 & 0.505 & 1.015 \\
Check OS & 14.4 & 54.29 & 86.59 & 7909 & 19.1 & 2.42 & 8.50 & 0.420 & 0.87 \\
\hline
\end{tabular}

Table 3. Composition (\%) and features $\left(\mathbf{T},{ }^{\circ} \mathrm{C}\right)$ of $\mathrm{OS}$ ash

\begin{tabular}{|c|c|c|c|c|c|c|c|c|}
\hline $\mathrm{SiO}_{2}$ & $\mathrm{Al}_{2} \mathrm{O}_{3}$ & $\mathrm{Fe}_{2} \mathrm{O}_{3}$ & $\mathrm{CaO}$ & $\mathrm{MgO}$ & $\mathrm{Na}_{2} \mathrm{O}+\mathrm{K}_{2} \mathrm{O}$ & $\mathrm{T}_{1}$ & $\mathrm{~T}_{2}$ & $\mathrm{~T}_{3}$ \\
\hline 55.18 & 17.20 & 9.73 & 12.44 & 2.66 & 2.52 & 1077 & 1153 & 1220 \\
\hline
\end{tabular}

\section{Selection of design parameters}

In order to get a well-designed CFB, some main parameters, such as fluidization velocity, bed temperature and ratio of primary/secondary air, should be selected correctly.

\section{Fluidization velocity}

Fluidization velocity is a crucial factor for a CFB boiler. If the velocity is too high, the boiler will be more compact. Therefore, the height of the boiler or cyclone efficiency must be increased for improving circulation rate, to make sure that fuel has enough residence time and to place ample heat surface in the furnace. This will result in a serious erosion and increase boiler's cost. 
Though combustion efficiency will rise to some degree, the overall efficiency of boiler island will not be increased accordingly because of losses of fan etc. On the contrary, if the velocity is too low, there will be a series of problems about combustion and heat transfer. So, the selection of fluidization velocity should keep a balance between the two aspects. The physical structure of OS particles takes sheet form after grinding, and the problem will become more serious with the increasing of particle size. It will cause short paths and dead zones in the dense zone if the operation velocity is not selected moderately. When designing a $65-\mathrm{t} / \mathrm{h}$ boiler, air velocity through nozzle orifices is about $58.9 \mathrm{~m} / \mathrm{s}$, and the superficial gas velocity at the bottom is preset at $4.5-5.0 \mathrm{~m} / \mathrm{s}$. The velocity can keep the fluidization uniform and stable, and decrease the erosion of the water wall. For the $65-\mathrm{t} / \mathrm{h}$ boiler, the cross section of $2.156 \mathrm{~m} \times 4.855 \mathrm{~m}$ in the lower furnace zone is used, and the height of the lower dense zone is $7.0 \mathrm{~m}$ to assure a long residence time of particles.

\section{Bed temperature}

The following factors should be considered in selection of bed temperature at designing of oil shale-fired CFB boiler: (1) bed temperature should be controlled for avoiding ash fusion and coking; (2) high desulphurization efficiency be ensured; (3) low emission of $\mathrm{NO}_{\mathrm{x}}$ be obtained; (4) volatilization of alkali metals be avoided. Thus, $850{ }^{\circ} \mathrm{C}$ is selected after a comprehensive consideration of all above factors.

\section{Ratio of primary/secondary air}

Dividing of combustion air into primary and secondary air can decrease $\mathrm{NO}_{\mathrm{x}}$ emission and fan loss. The ratio is decided by the following aspects: firstly, the stage combustion can help to decrease the emission of $\mathrm{NO}_{\mathrm{x}}$ to a lower level, especially in the case of high-volatile fuels. Hence, it is necessary to enhance the ratio of secondary air. Secondly, the primary air is generally fed into the furnace through the bottom of the air distributor keeping good fluidization of bed materials. This air has to overcome the additional resistance of the air distributor and the dense zone. The secondary air is usually injected into the furnace above the dense zone, and the primary blower loss will be reduced by increasing flow rate of the secondary air [7]. Finally, the low ratio of primary/secondary air does good to $\mathrm{NO}_{\mathrm{x}}$ emission and fan loss, but does harm to the fluidized fuel [8]. Above all, 60/40 as the ratio of the primary/secondary air is preset in design of $65-\mathrm{t} / \mathrm{h}$ oil shale-fired CFB boiler. The secondary air is injected into the furnace at three different heights, which can decrease the emission of $\mathrm{NO}_{\mathrm{x}}$. Adjusting the secondary air can maintain furnace temperature around $850{ }^{\circ} \mathrm{C}$ in a small range and increase superficial gas velocity at moving through the upper furnace, and realizes the lower temperature combustion of OS. 


\section{Self-desulphurization ability}

When OS burns, sulfur is oxidized primarily to sulfur dioxide $\left(\mathrm{SO}_{2}\right)$. It will cause serious pollution if all the sulfur dioxide is released into the atmosphere. Usually limestone is added for sulfur capture. In Huadian OS ash, the percent of alkaline material like $\mathrm{CaO}$ is up to $12.44 \%$ and $\mathrm{Ca} / \mathrm{S}$ molar ratio is up to 5.32. This will make self-desulphurization ability of OS high enough, and sulfur dioxide emission can be controlled at a lower level without adding sorbent [9].

\section{Velocity in back-pass}

For the $65-\mathrm{t} / \mathrm{h}$ oil shale-fired CFB boiler, the economizer and the air heater are located in the back pass. Ash content of Huadian OS is high - about 55\%. If the selected velocity of flue gas is too high, the erosion on economizer and air heater will be serious. Flue gas velocities are preset at $7.1 \mathrm{~m} / \mathrm{s}$ and $8.9 \mathrm{~m} / \mathrm{s}$ in economizer and air heater, respectively.

\section{Expert system}

CFBCADC [4-6] is a powerful tool for evaluation of bids for CFB boilers, which was developed by Greenfield Research Inc. (GRI) in collaboration with DalTech Dalhousie University and Electricite de France to support fluidized-bed operators and boiler designers from Europe, North America, and Asia. It is also a commercially available expert system for evaluation of the design of circulating fluidized bed boilers.

CFBCAD $C$ can produce an optimum design of the entire boiler for the specified design and specified fuel. This allows an independent benchmark to compare the submitted designs. Furthermore, CFBCAD $\subset$ also allows the boiler purchaser to produce virtual bids using different technologies for purchaser specific case well before tenders are invited and to use that to prepare the boiler specification accordingly. When a boiler user or purchaser receives a number of bids from different manufacturers using different design philosophies, it becomes very difficult for the purchaser to compare them on a common and even base. This option not only provides the purchaser with a benchmark for every type of design, it also allows one to better appreciate the merit and demerits of different types of designs for a specific situation. The model uses user-inputted fuel specifications and steam conditions to size the furnace and calculate heat transfer surfaces. A variety of heat transfer surface configurations is available for analysis. It has been used to evaluate the design of some operating plants and to try and predict deviations from design parameters. 


\section{Results and discussion}

\section{Comparison between manual and expert system}

In order to prove the validity of the expert system for oil shale-fired CFB boiler design and to broaden the range of its use, the system was used to regenerate and evaluate the manual design of the $65-\mathrm{t} / \mathrm{h}$ oil shale-fired CFB boiler. Required input parameters are given in Tables 1 and 2. The comparison results are discussed as follows:

\section{Comparison of heat duty distribution}

Figure 2 compares the heat duty distributions of water wall (WW), superheater $(\mathrm{SH})$, economizer $(\mathrm{ECO})$ and air heater $(\mathrm{AH})$ computed by manual and CFBCAD. One can see that the heat duties in economizer and air heater are similar. The small difference is the reflection of the difference in design choices. However, differences in heat duty for water wall and superheater are significant. The expert system makes greater use of furnace water wall and less of the superheater. For $65-\mathrm{t} / \mathrm{h}$ oil shale-fired CFB boiler, the superheater is located in he upper furnace. However, it is located in the backpass using CFBCAD. Although different arrangement of this component affects the heat duty distribution, the sum of heat duty of water wall and uperheater is similar on the basis of manual design and Expert System design.

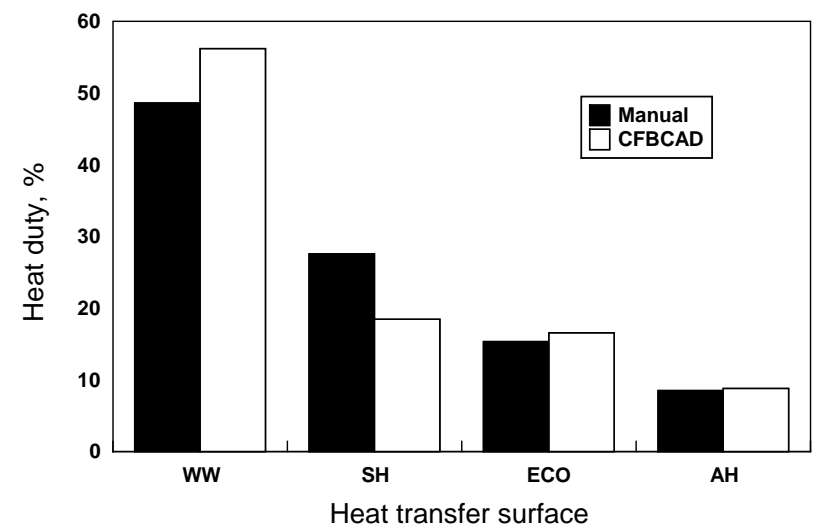

Fig. 2. Heat duty distribution.

\section{Heat transfer surface}

Heat transfer surface areas, computed by two methods, are given in Fig. 3. Results for all elements are similar and the small difference is within the error range. The integrated effect of heat duty distribution and the heattransfer coefficient make water wall and superheater surface similar even in the case of a significant difference in heat duty, which can prove the validity of CFBCAD on design oil shale-fired CFB boiler. 


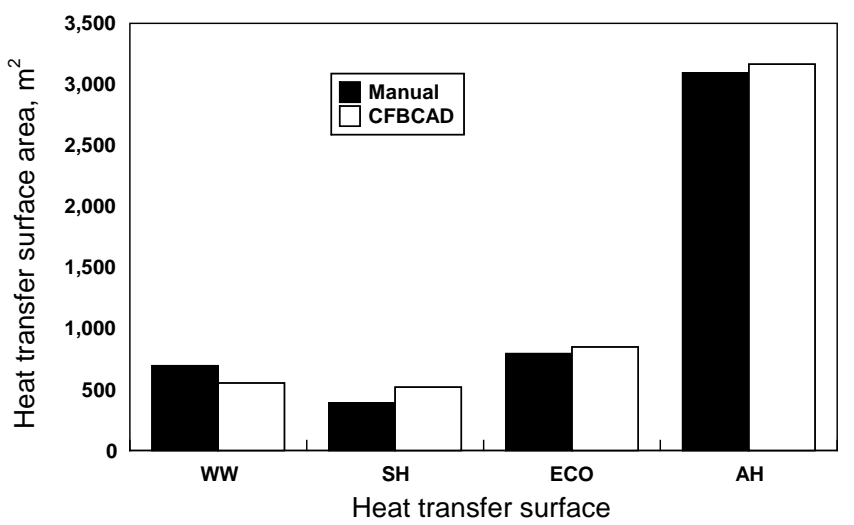

Fig. 3. Heat transfer surface areas.

\section{Main dimensions in furnace}

The main dimensions obtained by manual and CFBCAD are listed in Table 4 . The shape of furnace, which depends to some extent on the preferences of the designers, is different (width-depth ratio), but the cross-section and height are similar because of similar fluidization velocity.

Table 4. Main dimensions in furnace

\begin{tabular}{|l|c|c|}
\hline & Manual & CFBCAD \\
\hline Cross section, $\mathrm{m}^{2}$ & 23.1 & 22.13 \\
Width, m & 4.855 & 6.13 \\
Breadth, $\mathrm{m}$ & 4.75 & 3.608 \\
Height, $\mathrm{m}$ & 32.75 & 30.95 \\
Distributor cross section, $\mathrm{m}^{2}$ & 10.47 & 8.30 \\
Breadth of distributor, $\mathrm{m}$ & 2.16 & 1.35 \\
\hline
\end{tabular}

\section{Analysis of operation performance}

Three 65-t/h oil shale-fired CFB boilers have been constructed in 1996 and put into stable operation for twelve years in Huadian city, Jilin Province. Operation results showed high combustion efficiency and good operation identity of the boiler. Many tests have been done: (1) start-up characteristics; (2) bed temperature; (3) ability of self-desulphurization; (4) thermal losses; and (5) temperature distribution.

\section{Start-up characteristics}

There are two oil start-up burners placed in side walls $(1675 \mathrm{~mm}$ above the distributor). One burner is set to work to heat bed material, the second one will not be put into operation until bed material has reached $300{ }^{\circ} \mathrm{C}$. When the bed material temperature has reached $500-550^{\circ} \mathrm{C}$, OS is launched into the furnace gradually, then the burner is put off when bed temperature reaches $850^{\circ} \mathrm{C}$. 
Figure 4 shows the temperature changes in the furnace exit and the fluidized bed. The bed temperatures are measured at the same level $(300 \mathrm{~mm}$ above the distributor) of three different positions - front, back and right side of the dense zone. It can be seen that the heating rate of the bed material changes more quickly below $400{ }^{\circ} \mathrm{C}$. Between $400{ }^{\circ} \mathrm{C}-500{ }^{\circ} \mathrm{C}$, bed temperature rises quickly. This is because the feed ignite coal (bituminous coal) starts to burn in the furnace. After reaching $500^{\circ} \mathrm{C}$, OS is fed into the furnace and bed temperature rises sharply. The primary air flux should be increased to control the rate of temperature rise to avoid coking in the furnace at the same time. A small difference in temperature change measured simultaneously proves a good fluidization quality in the bed during the start-up process. When the bed temperature reaches about $850{ }^{\circ} \mathrm{C}$, OS feed becomes normal and combustion in the boiler becomes steady, two oil burners also be stopped. In addition, the furnace exit temperature increases gradually during the start-up process, and there is no sharp change, which shows the perfect cold start-up characteristics of the oil shale-fired CFB boiler.

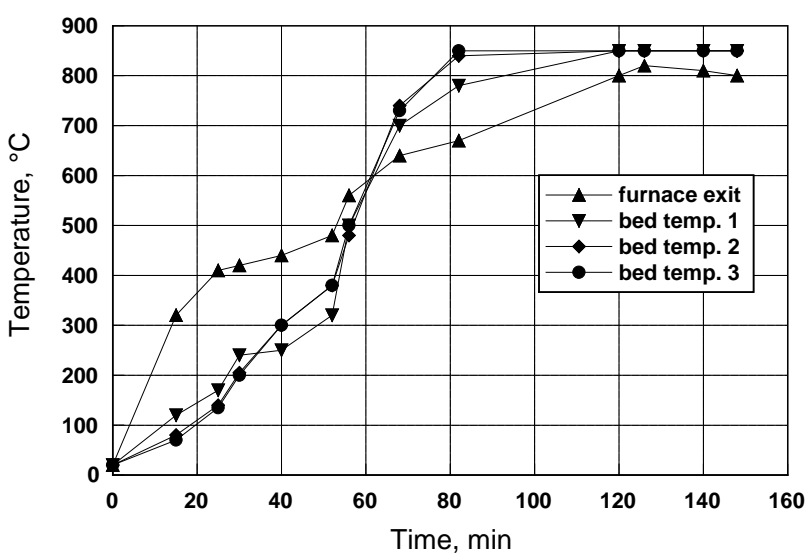

Fig. 4. Boiler cold start-up feature.

\section{Bed temperature}

Combustion of fuel in the furnace has an immediate relationship with the economic and natural operation of boiler. Bed temperature is one of the most important control variables, which has an effect on combustion efficiency, heat transfer, desulphurization and overall operation capability. When the load changes, feed fuel, feed air, bed height, circulating ash, operation velocity and bed temperature will change accordingly. Figure 5 shows the relationship between load and bed temperature. At 30\% load, the bed temperature is about $800^{\circ} \mathrm{C}$, while circulation of solids stops. With the increasing of load, bed temperature also increases. When the boiler operates between $50 \%-110 \%$ load, bed temperature stables basically at $850{ }^{\circ} \mathrm{C}$. Beyond $110 \%$ load, bed temperature increases sharply with load. The boiler holds perfect temperature identity. 


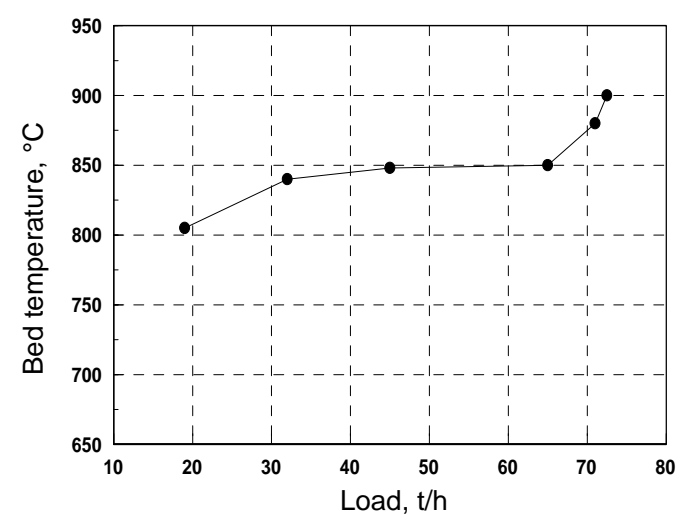

Fig. 5. Relationship between boiler load capacity and bed temperature.

\section{Self-desulphurization}

$\mathrm{Ca} / \mathrm{S}$ molar ratio in Huadian OS is up to 5.32. The self-desulphurization efficiency can reach $96 \%$ without adding a sorbent. Figure 6 shows the change of self-desulphurization efficiency with different bed temperatures. At a temperature lower than $850^{\circ} \mathrm{C}$, the efficiency increases along with the bed temperature increasing, and the efficiency decreases along with bed temperature increasing when the temperature exceeds $850^{\circ} \mathrm{C}$. It can be seen that $850^{\circ} \mathrm{C}$ is the optimal temperature for self-desulphurization of Huadian OS.

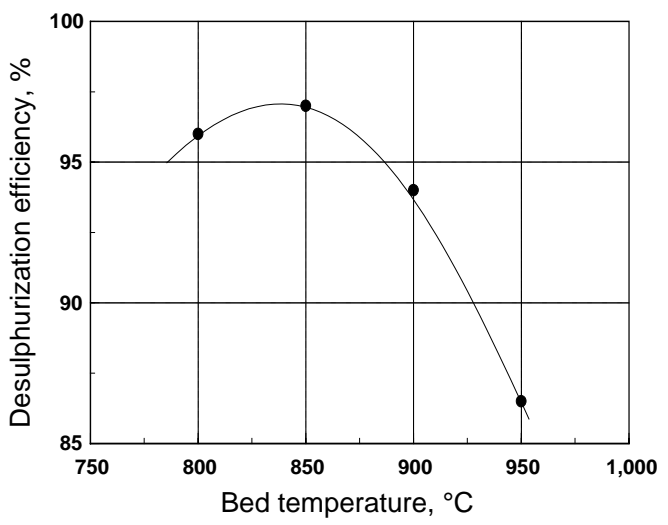

Fig. 6. Effect of bed temperature on self-desulphurizaton of Huadian oil shale.

\section{Heat loss}

Figure 7 gives the heat loss with boiler load. With the increasing of load, flue gas loss $\left(\mathrm{q}_{2}\right)$ increases, and three other losses $\left(\mathrm{q}_{4}, \mathrm{q}_{5}, \mathrm{q}_{6}\right)$ have no significant change at different load. When load changes from $70 \%$ to $110 \%$ load, stack temperature also increases, which results in the increasing of flue gas loss decided by stack temperature. 


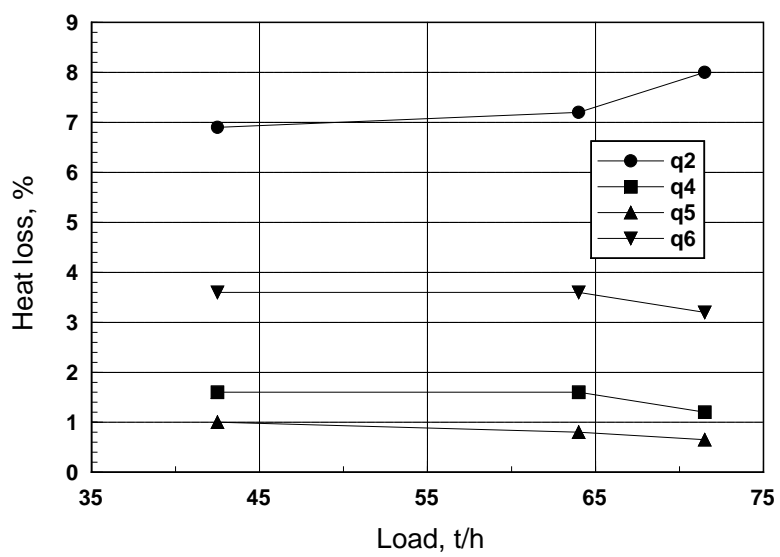

Fig. 7. Heat losses change with loads.

\section{Temperature distribution in back-pass}

Figure 8 shows the temperature profiles at different loads in the backpass. With the increasing of load, the temperature of flue gas in the backpass increases accordingly, but falls gradually along the backpass. At $100 \%$ load, the temperature inosculates with design value.

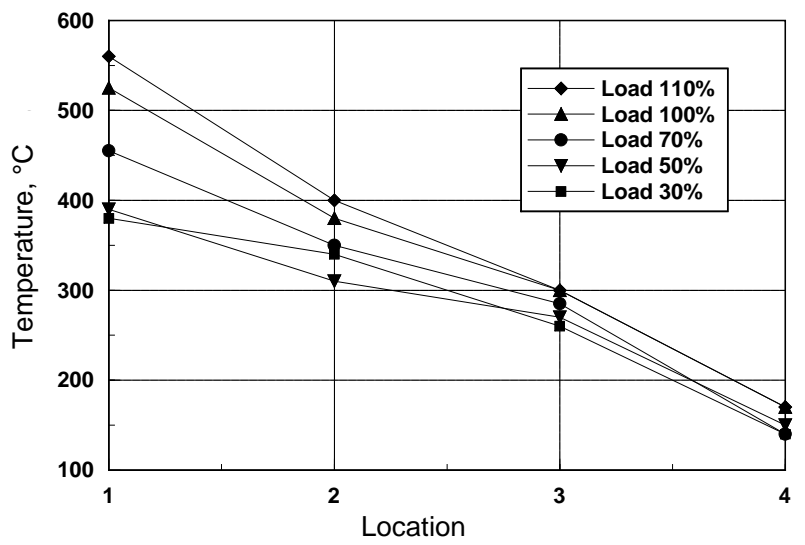

Fig. 8. Temperature change for different loads in the backpass. 1 - entrance of high economizer; 2 - exit of high economizer; 3 - exit of low economizer; 4 - exit of air heater.

\section{Conclusions}

Design considerations and methods have been discussed for $65-\mathrm{t} / \mathrm{h}$ oil shalefired CFB boilers, which have been successfully in stable commercial operation for twelve years in Huadian city, Jilin province, China. Operation results indicated that OS could be used as a fuel in power boiler, and the circulating 
fluidized bed boiler was the best selection to burn it, and all the parameters could reach the designed values. The design results predicated by the expert system were compared with those of a manual design procedure and found to be in good agreement. It was also proved that the Expert system could be used to design oil shale-fired CFB boilers.

\section{Acknowledgements}

Authors are grateful for financial support from Jilin Province Science and Technology Department (20065022).

\section{REFERENCES}

1. Wang, Q., Hao, Z. J., Sun, J., Qin, Y. K. Operating performance analysis of an oil shale fired circulating fluidized bed boiler of the highest capacity currently in operation in China // Journal of Engineering for Thermal Energy \& Power. 2001. Vol. 16, No. 5. P. 513-516 [in Chinese].

2. Holopainen, $H$. Experience of oil shale combustion in Ahlstrom pyroflow CFB-boiler // Oil Shale. 1991. Vol. 8, No. 3. P. 194-209.

3. Loosaar, J., Arro, H., Parve, T., Pihu, T., Prikk, A., Tiikma, T., Hiltunen, M. New $215 \mathrm{MW}_{\mathrm{EL}}$ CFB power units for Estonian oil shale // Proceedings of the 18th International Conference on Fluidized Bed Combustion, Toronto, Ontario (Canada), May 22-25, 2005. ASME, New York, CD-ROM, ISBN 0-79183755-6. FBC2005-78141. 12 p. http://www.asmeconferences.org/FBC05/ TechnicalProgramOverview.cfm\#1.

4. Lafanechère, L., Basu, P., Jestin, L. The effect of fuel parameters on the size and configuration of circulating fluidized-bed boilers // J. Inst. Energy. 1995. Vol. 68, No. 477. P. 184-192.

5. Lafanechère, L., Jestin, L. Study of a circulating fluidized bed furnace behavior in order to scale it up to 600 Mwe // Proceeding of the 13th International Conference on Fluidized Bed Combustion /K. J. Heinschel (ed.). New York: ASME, 1995. Vol. II. P. 971-980.

6. Lafanechère, L., Basu, P., Jestin, L. Use of an expert system to study the effect of steam parameters on the size and configuration of circulating fluidized bed boilers // Journal of Engineering for Gas Turbines and Power. 1998. Vol. 120, No. 4. P. 861-866.

7. Basu, P., Fraser, S. A. Circulating Fluidized Bed Boiler: Design and Operation. - Boston: Butterworth-Heinemann, 1991. P. 163-193.

8. Cen, K. F. Overall design of the circulating fluidized bed // Theory, Design and Operation of CFB Boiler/China Electricity Press, 1998. P. 480-481 [in Chinese].

9. Jing, X. M., Wang, Q., Zhang, J. B. Design and operation for oil shale CFB boiler // Power Engineering. 1998. Vol. 8, No. 3. P. 22-28 [in Chinese].

Presented by J. L.Qian

Received February 27, 2008 